\title{
ESPINHA BIFIDA OCULTA E DISTÚRBIOS NEUROLÓGICOS NA RAQUEANESTESIA. CONSIDERAÇõES A PROPÓSITO DE 8 CASOS
}

\author{
DANTE GIORGI * \\ JAYME NASSER * \\ Aldo R. Bevilacqua **
}

$O$ presente trabalho não se destina a descrever as seqüelas da raqueanestesia nem estudar as malformações congênitas da medula; êle visa 3 chamar a atenção sôbre a freqüência com que ocorrem seqüelas nos pacientes portadores de espinha bífida oculta submetidos a raqueanestesia.

Entre as anomalias congênitas do sistema nervoso central, são os distúrbios de desenvolvimento da medula os mais freqüentes e a espinha bífida a mais encontradiça. A causa destas anomalias é desconhecida, ignorando-se se são decorrentes da ação de um agente externo atuando após fertilização normal, ou se são a conseqüência de um defeito dos gens. Conforme a época em que se instalam as lesões que as determinam, as malformações assumem caracteres diversos, sendo tanto mais graves quanto mais precocemente se tiverem instalado.

As malformaçōes medulares podem ser classificadas em dois grupos principais ${ }^{13}$ :

A. Malformações em épocas precoces do desenvolvimento embrionário (incompativeis com a vida): a) amielia; b) raquisquise posterior completa.

B. Malformações en épocas mais tardias do desenvolvimento embrionário: a) afetando só a medula (diplomielia); b) lesando a medula e seus envoltórios (mielocele, siringomielocele, meningomielocele); c) afetando apenas os envoltórios (meningocele); d) defeito no fechamento dos arcos vertebrais (spina bifida oculta): e) defeito no fechamento ectodérmico-epitelial (seios cutâneos).

A designação espinha bífida oculta abrange as malformações em que estão presentes defeitos de fusão da coluna vertebral, sem protrusão do conteúdo espinal para a superfície. A maioria destas malformações ocorre na região lombossacra; freqüentemente elas não determinam sintomatologia neurológica. Algumas vêzes a espinha bifida oculta se acompanha de sintomas cutâneos (tufos anormais de pêlos, angiomas, lipomas e seios cutâneos). Em certos casos ocorrem alteraçōes músculo-esqueléticas (fraqueza muscular, deformidades da articulação coxofemoral) e, algumas vêzes, ocorrem distürbios esfinctéricos e da potência sexual (retardo na aquisição ou

Trabalho do Serviço de Neurologia da Escola Paulista de Medicina (Prof. Paulino W. Longo). *Assistente; ** Médico interno. 
rєgressão de hábitos adquiridos no contrôle esfinctérico, incontinência urinária por pressão abdominal e relaxamento do esfincter anal).

Pelo fato do mesoderma - de onde se originam os ossos da coluna vertebral - dar origem a tecido gorduroso e fibroso, ao córion e vasos sangüineos, é freqüente serem encontradas anomalias dessas estruturas acompanhando os defeitos ósseos. Tais anomalias, quando situadas dentro do canal raqueano, comportam-se como tumores e daí, então, a necessidade da exploração cuidadosa de todos os pacientes portadores de espinha bífida com sintomatologia neurológica.

Seqüelas de raqueanestesia, qualquer que seja o anestésico utilizado, vêm sendo referidas e discutidas desde a introdução desta técnica de anestesia. Em 2.493 pacientes operados com raqueanestesia, Thorsen ${ }^{15}$ encontrou sintomas de lesões da substância medular, das raízes nervosas e da cauda eqüina, na proporção de 1 para 200 .

As objeções à raqueanestesia partem, principalmente, dos neurologistas, para os quais convergem os pacientes portadores de seqüelas. A cefaléia, freqüentemente observada após a raqueanestesia, não é considerada por nós como seqüela, podendo ser ligada à própria punção lombar.

As seqüelas por nós referidas estão ligadas à função esfinctérica, à potência sexual e à diminuição da fôrça muscular dos membros inferiores. Foster Kennedy e Effron ${ }^{7}$ afirmam que os riscos a que está sujeito o paciente submetido à raqueanestesia constituem um preço muito elevado para que o cirurgião obtenha um silêncio operatório e, ao mesmo tempo, afirmam que tal anestesia deve ser reservada, única e exclusivamente, aos casos que não possam ser submetidos à anestesia local ou geral. Schaltenbrand ${ }^{9}$ refere que a raqueanestesia não é mais usada na Alemanha; Mac Donald ${ }^{8}$ afirma que, na Inglaterra, tal método não é popular por temerem os cirurgiões as seqüelas. A maior contraindicação da raqueanestesia é em relação aos pacientes com síndromes neurológicas, principalmente medulares ${ }^{12}$. A anestesia raqueana não deve ser dada a pacientes com moléstia medular reconhecida, com hérnia de disco intervertebral, com paralisia de nervos periféricos, com distúrbios das funções da bexiga e dos intestinos, com taxas elevadas de proteína no líqüido cefalorraqueano ${ }^{12}$.

Seqüelas de raqueanestesia foram verificadas por nós em pacientes portadores de espinha bífida oculta assintomática. Poucos são os autores que chamam a atenção sôbre a espinha bifida oculta assintomática e sôbre os perigos da raqueanestesia em tais casos. Dumont, em citação que encontramos no Quarterly Index Medicus (Dumont, A. D. - Nervous disturbances of radicular origin following spinal anesthesia in two patients with spina bifida oculta. J. de Chir. et Ann. Soc. Belge de Chir., 36, $34: 31-39$, janeiro 1937), faz referência a dois casos de espinha bífida oculta que apresentaram distúrbios neurológicos de tipo radicular após raqueanestesia; infelizmente, não conseguimos compulsar êsse trabalho por não existir entre nós a revista citada. 
Nos tratados de anestesiologia $3,5,10,16$ ou de malformações do sistema nervoso ${ }^{1,2,4,6,13}$ habitualmente consultados, não há referência à relação entre espinha bifida oculta e as seqüelas de raqueanestesia. A única contra-indicação formal da raqueanestesia, em portadores de espinha bífidá oculta, é feita por Maffei ${ }^{11}$, que refere casos de seqüelas graves, e mesmo de morte.

Sendo a espinha bifida oculta uma ocorrência freqüente - chegando alguns autores ${ }^{\circ}$ a afirmar que esta anomalia atinge $25 \%$ dos indivíduos, enquanto outros ${ }^{13}$ dão valores mais baixos, 1:800 - e a raqueanestesia uma técnica muito usada entre nós, é de supor que as seqüelas após anestesia sejam mais freqüentes do que admitem os cirurgiões. Se indivíduos normais não devem ser expostos aos riscos da raqueanestesia, com muito mais razão os portadores de anomalias do sistema nervoso.

Partindo das conclusões de Maffei ${ }^{11}$, um de nós examinou, radiològicarnente, 11 pacientes que apresentaram seqüelas de raqueanestesia, verificando, em grande percentagem $(8: 11)$, a presença de espinha bifida oculta; em um dos 3 casos que não apresentava tal anomalia a anamnese revelou enurese até os 18 anos de idade. Em dois casos nada foi apurado que levasse a pensar em malformação; um dêstes casos evoluiu como aracnoidite. O quadro 1 sintetiza nossas observações:

A alta percentagem verificada parece mostrar uma relação direta entre espinha bifida oculta e raqueanestesia. Temos a impressão de que os individuos portadores de espinha bífida oculta, indicando uma malformação, são mais sensiveis ao anestésico; assim, uma dose que individuos normais toleram sem seqüelas, determina, nos portadores de anomalias, alterações graves e duradouras, por vêzes irreversiveis.

Êstes fatos exigem dos cirurgiões uma atenção especial: a anamnese deve ser cuidadosa, na investigação de distúrbios do contrôle esfinctérico na infância, e o exame clínico, completado pelo exame radiográfico, deve ser minucioso na pesquisa de malformaçōes cutâneas ou músculo-esqueléticas, características dêstes distúrbios de desenvolvimento, antes de ser indicada uma anestesia raqueana.

\section{RESUMO}

São relatados 11 casos de seqüelas de raqueanestesia observados no Serviço de Neurologia de um hospital geral. Em 8 casos o exame radiológico mostrou a existência de espinha bífida oculta; em um caso a anamnese assinalou a ocorrência de enurese até os 18 anos de idade. Os autores chamam a atenção para êste fato e correlacionam a preexistência de malformação do sistema nervoso central à alta incidência das seqüelas. Por êsse motivo aconselham a pesquisa dessas alterações, clínica e radiològicamente, antes de ser indicada a raqueanestesia. 


\begin{tabular}{|c|c|c|c|c|}
\hline Caso & $\begin{array}{l}\text { Data da } \\
\text { operacão }\end{array}$ & $\begin{array}{l}\text { Exame } \\
\text { neurológico }\end{array}$ & Seqüelas & $\begin{array}{l}\text { Radiografia da } \\
\text { coluna vertebral }\end{array}$ \\
\hline $\begin{array}{l}\text { J.F.S. } \\
111029\end{array}$ & $\begin{array}{c}\text { Dezembro } \\
1952\end{array}$ & $\begin{array}{c}\text { Marco } \\
1953\end{array}$ & $\begin{array}{l}\text { Distúrbios da miccão e } \\
\text { da defecacão **. }\end{array}$ & Espinha bifida \\
\hline $\begin{array}{l}\text { N.C. } \\
92419\end{array}$ & $\begin{array}{c}\text { Novembro } \\
1950\end{array}$ & $\begin{array}{c}\text { Novembro } \\
1951\end{array}$ & $\begin{array}{l}\text { Dôres lombares e distúr- } \\
\text { bios da micção }\end{array}$ & Espinha bifida \\
\hline $\begin{array}{l}\text { V.V. } \\
55600\end{array}$ & $\begin{array}{c}\text { Setembro } \\
1951\end{array}$ & $\begin{array}{l}\text { Outubro } \\
1951\end{array}$ & Dôres lombares. & Espinha bifida \\
\hline $\begin{array}{l}\text { A.T. } \\
604\end{array}$ & 1935 & $\begin{array}{l}\text { Maio } \\
1947\end{array}$ & Distúrbios da micção **. & Espinha bifida \\
\hline $\begin{array}{l}\text { S.S.A. } \\
174379\end{array}$ & $\begin{array}{l}\text { Março } \\
1956\end{array}$ & $\begin{array}{l}\text { Outubro } \\
1956\end{array}$ & Dôres lombares. & Espinha bífida \\
\hline $\begin{array}{l}\text { H.G. } \\
83801\end{array}$ & 1950 & $\begin{array}{c}\text { Abril } \\
1955\end{array}$ & $\begin{array}{l}\text { Paresia do membro infe- } \\
\text { rior esquerdo. Impotên- } \\
\text { cia sexual. }\end{array}$ & Espinha bifida \\
\hline $\begin{array}{l}\text { J.N. } \\
111168\end{array}$ & $\begin{array}{c}\text { Fevereiro } \\
1953\end{array}$ & $\begin{array}{l}\text { Março } \\
1953\end{array}$ & $\begin{array}{l}\text { Dor na panturrilha di- } \\
\text { reita. }\end{array}$ & Espinha bifida \\
\hline $\begin{array}{l}\text { J.M.S. } \\
147600\end{array}$ & 1948 & $\begin{array}{c}\text { Novembro } \\
1954\end{array}$ & $\begin{array}{l}\text { Paresia e hipoestesia do } \\
\text { membro inferior esquer- } \\
\text { do. Impotência sexual. }\end{array}$ & Espinha bifida \\
\hline $\begin{array}{l}\text { J.P.G. } \\
256270\end{array}$ & $\begin{array}{c}\text { Marco } \\
1959\end{array}$ & $\begin{array}{l}\text { Maio } \\
1959\end{array}$ & $\begin{array}{l}\text { Diminuição da fôrça nos } \\
\text { membros inferiores. }\end{array}$ & Normal * \\
\hline $\begin{array}{l}\text { J.M. } \\
77727\end{array}$ & $\begin{array}{l}\text { Janeiro } \\
1951\end{array}$ & $\begin{array}{c}\text { Setembro } \\
1951\end{array}$ & $\begin{array}{l}\text { Paraplegia espástica. } \\
\text { Aracnoidite. }\end{array}$ & Normal \\
\hline $\begin{array}{l}\text { B.E.S. } \\
282696\end{array}$ & $\begin{array}{l}\text { Outubro } \\
1958\end{array}$ & $\begin{array}{l}\text { Abril } \\
1959\end{array}$ & $\begin{array}{l}\text { Sensações parestésicas nos } \\
\text { membros inferiores. Re- } \\
\text { flexos aquilianos aboli- } \\
\text { dos. }\end{array}$ & Normal \\
\hline
\end{tabular}

Quadro 1 - Seqüelas neurológicas permanentes de raqueanestesia mostrando a freqüência com que foi assinalada espinha bífida. Todos os pacientes são registrados na Clinica Neurológica do Instituto de Aposentadoria e Pensōes dos Comerciários em São Paulo. * Este paciente apresentou enurese até os 18 anos de idade. ** Estes pacientes não foram submetidos a intervenção sôbre o tracto geniturinário nem sôbre as porções terminais do aparelho digestivo. 


\section{SUMMARY}

Spina bifida occulta in cases of neurological sequelae after rachianesthesia.

Report of 11 cases with neurological sequelae after rachianesthesia. The neurological symptoms were: root pains, sexual impotence, weakness of the lower limbs and sphincter disturbances. None of these patients had any neurological symptom before the administration of spinal anesthetic. Eight patients presented spina bifida occulta without neurological signs. Of the 3 cases with normal roentgenogram one had enuresis until 18 years old. The authors suggest that clinical and roentgenogram studies should be done before each rachianesthesia procedure.

\section{REFERENCIAS}

1. ALBEE, F. H.; POWERS, E. J.; McDOWELL, H. C. - Surgery of the Spinal Column. F. A. Davis Co., Filadéifia, 1945. 2. BANCROFT, F. W.; COBB, P. Surgical Treatment of the Nervous System. J. B. Lippincot Co., Filadélfia-LondresMontreal, 1946. 3. DOGLIOTTI, A. M. - Trattado di Anestesia. U.T.E.T., Torino, 1935. 4. ELSBERG, C. A.; DYKE, C. G.; WOLF, A. - Surgical Diseases of Spinal Cord, Membranes and Nerve Roots. Paul B. Hoeber Inc., Nova York, 1941. 5. HALE, D. E. - Anesthesiology. F. A. Davis Co., Filadélfia, 1945. 6. INGRAHAM, F. D.; MATSON, D. D. - Neurosurgery of Infancy and Childhood. Charles C. Thomas, Springfield, 1954. 7. KENNEDY, F.; EFFRON, A. S.; GERALD, P. - Grave spinal cord paralysis caused by spinal anesthesia. Surg., Gynec. a. Obst., 91:385398, outubro 1950. Comentado em Year-Book of Neurology, Psychiatry and Neurosurgery, pág. 115, 1950. 8. MAC DONALD, A. D. - Some problems of experimental spinal anesthesia. In Ciba Foundation Symposium on The Cerebrospinal Fluid. J. \& A. Churchill Ltd., Londres, 1958, pág. 3089. SCHALTENBRAND, G. - In Ciba Foundation Symposium on the Cerebrospinal Fluid. J. \& A. Churchill Ltd., Londres, 1958, pág. 308. 10. MACINTOSH, R. R. - Lumbar Puncture and Spinal Analgesia. E. \& S. Livingstone Ltd., Edimburgo, 1951. 11. MAFFEI, W. E. - As Bases Anátomo-Patológicas da Neuriatria e Psiquiatria. Imprensa Metodista, São Paulo, 1951. 12. NICHOLSON, M. J.; EVERSOLE, U. H. - Neurologic complications of spinal anesthesia. J.A.M.A., 132:679-685 (novembro, 23) 1946. Comentado em Year-Book of Neurology, Psychiatry and Neurosurgery, pág. 181, 1946. 13. OBRADOR, S.; ALBERT, P.; ANASTACIO, J. V.; ARRAZOLA, M.; BOIXADOS, J. R.; SANCHES JUAN, J.; VASQUES AÑON, J. J. - Sindromes Neurológicos en las Malformaciones y Lesiones Degenerativas del Estuche Cráneo-vertebral y su Tratamiento Neuroquirúrgico. Editorial Paz Montalvo, Madrid, 1956. 14. PHILIP, L. - Backache and Sciatic Neuritis. Lea \& Febiger, Filadélfia, 1946. 15. THORSEN, G. - Neurologic complications after spinal anesthesia. Acta Chir. Scandinav., supl .121, vol. 95, 1947. Comentado em Year-Book of Neurology, Psychiatry and Neurosurgery, pág. 171, 1947 . 16. TUFFIER - La Rachicocaïnisation. Masson et Cie., Paris, 1904.

Serviço de Neurologia da Escola Paulista de Medicina - Caixa Postal 5496 Sāo Paulo, Brasil. 